Cite this: RSC Advances, 2013, 3, 9296

Received 17th January 2013,

Accepted 26th March 2013

DOI: $10.1039 / \mathrm{c} 3 \mathrm{ra} 40241 \mathrm{j}$

www.rsc.org/advances

\title{
Complexation of trivalent lanthanides and actinides with several novel diglycolamide-functionalized calix[4]arenes: solvent extraction, luminescence and theoretical studies $\dagger$
}

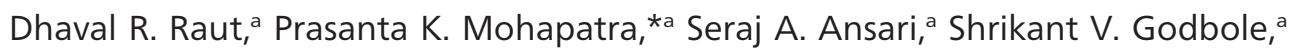 \\ Mudassir Iqbal, ${ }^{\text {b }}$ Debashree Manna, ${ }^{c}$ Tapan K. Ghanty, ${ }^{c}$ Jurriaan Huskens ${ }^{\text {b }}$ \\ and Willem Verboom ${ }^{b}$
}

\begin{abstract}
Several diglycolamide-functionalized calix[4]arenes (DGA-Calix) were evaluated for actinide extraction from acidic feeds. The ligands with four diglycolamide (DGA) pendent arms are significantly more effective extractants than those with two DGA pendent arms. The ligands have a preference for the extraction of $\mathrm{Eu}^{3+}$, a representative trivalent lanthanide ion, as compared to $\mathrm{Am}^{3+}$, a commonly encountered trivalent actinide ion. The role of organic diluents on the metal ion extraction was investigated and the results were compared with the widely studied DGA-based extractant TODGA ( $N, N, N^{\prime}, N^{\prime}$-tetra- $n$-octyl diglycolamide). Time resolved laser fluorescence spectroscopy (TRLFS) studies showed a strong complexation with no inner-sphere water molecules in the Eu(III)-DGA-Calix complexes and the complex formation constants $(\log \beta)$ were calculated. Ab initio density functional calculations were carried out to explain the higher stability of the Eu-complex of the DGA-Calix ligand with four pendent arms as compared to the one with two pendent arms.
\end{abstract}

\section{Introduction}

Actinide ion extraction from acidic feeds is one of the most challenging problems encountered by separation scientists engaged in the task of radioactive waste remediation for the mitigation of the long term hazards of long-lived radionuclides including minor actinides and fission product nuclides. ${ }^{1}$ Diglycolamide-based extractants such as TODGA $\left(N, N, N^{\prime}\right.$, $N^{\prime}$-tetra- $n$-octyl diglycolamide) and T2EHDGA $\left(N, N, N^{\prime}, N^{\prime}\right.$-tetra2-ethylhexyl diglycolamide) have been employed for actinide partitioning from moderately acidic feed conditions. ${ }^{2}$ Apart from being far more efficient extractants for minor actinides than well-studied ligands such as CMPO (carbamoylmethylphosphinoxide), TRPO (trialkyl phosphinoxide), malonamide, and DIDPA (diisodecyl phosphoric acid), the diglycolamides display several unusual characteristics. ${ }^{3}$ These include higher extractability for trivalent ions as compared to the tetra- as well as hexavalent actinide ions, and size selective complexation.

${ }^{a}$ Radiochemistry Division, Bhabha Atomic Research Centre, Trombay, Mumbai400085, India. E-mail: mpatra@barc.gov.in; Fax: +91-22-25505151

${ }^{b}$ Laboratory of Molecular Nanofabrication, MESA+ Institute for Nanotechnology, University of Twente, P.O. Box 217, 7500 AE Enschede, The Netherlands

${ }^{c}$ Theoretical Chemistry Section, Bhabha Atomic Research Centre, Trombay, Mumbai400085, India

† Electronic supplementary information (ESI) available. See DOI: 10.1039/ c3ra40241j
This has been attributed to a reverse micellar extraction mechanism in non-polar diluents such as n-dodecane, which possibly helps in the formation of aggregates containing four diglycolamide (DGA) molecules. ${ }^{4}$ In view of the strong diluent dependence of this aggregate formation, ligands containing four DGA units appended to a calix[4]arene scaffold were synthesized. ${ }^{5}$ This would possibly make the selectivity displayed by the DGA-based extractants independent of the diluent characteristics. However, similar attempts to graft CMPO moieties onto a calix[4]arene scaffold were not very successful. ${ }^{6}$ In view of the size selective nature of the DGA aggregates, it was expected that the diglycolamide-functionalized calix[4]arenes may display extraction/complexation properties in variance to those of the CMPO-functionalized calix[4]arenes.

We have recently reported the synthesis and actinide extraction behaviour of several DGA-functionalized calix[4]arenes, termed for simplicity as DGA-Calix ligands, which were found to be far superior to TODGA and exhibited a comparable $\mathrm{Am}^{3+}$ extraction at a 100 times lower concentration than TODGA. ${ }^{7}$ Preliminary time-resolved laser-induced fluorescence spectroscopy (TRLIFS) studies of the $\mathrm{Eu}^{3+}$-DGA-Calix complexes indicated strong complexation with no inner-sphere water molecules. ${ }^{5}$ Several literature reports exist on the use of fluorescence spectroscopic data for the calculation of complex 
formation constants. ${ }^{8}$ In the present study an attempt was made to understand the luminescence properties of the $\mathrm{Eu}^{3+}-$ DGA-Calix complexes. These efforts include complex formation constant calculations as well as structural information based on the ${ }^{7} \mathrm{~F}_{2} \rightarrow{ }^{5} \mathrm{D}_{0}$ emission lines of the Eu(III)-DGA-Calix complexes.

The present work also deals with solvent extraction studies involving $\mathrm{Am}^{3+}$ and $\mathrm{Eu}^{3+}$ and comparison of the separation factors (SFs) under various experimental conditions involving the DGA-Calix ligands $\mathbf{L}_{\mathbf{I}}-\mathbf{L}_{\mathbf{I I I}}$ (Fig. 1) and TODGA. Ab initio density functional calculations were performed to gain insight into the structure of the $\mathrm{Eu}^{3+}$-complexes with these ligands.

\section{Experimental}

\subsection{Materials}

The DGA-functionalized calix[4]arene ligands $\mathbf{L}_{\mathbf{I}}-\mathbf{L}_{\text {III }}$ were synthesized as reported previously. ${ }^{7}$ The ligands were characterized using NMR and ESI-MS. ${ }^{241} \mathrm{Am}, \mathrm{Pu}$ (mainly ${ }^{239} \mathrm{Pu}$ ), and ${ }^{233} \mathrm{U}$ tracers were purified following standard procedures reported earlier, and the radiochemical purity of the tracers was checked using alpha-spectroscopy. ${ }^{9}$ A ${ }^{152,154} \mathrm{Eu}$ tracer, purchased from BRIT, Mumbai, was used after ascertaining its radiochemical purity by gamma-spectrometry using an HPGe detector. Assaying of ${ }^{241} \mathrm{Am}$ and ${ }^{152,154} \mathrm{Eu}$ was done by gamma counting using a $\mathrm{NaI}(\mathrm{Tl})$ scintillation counter, while nuclides such as ${ }^{239} \mathrm{Pu}$ and ${ }^{233} \mathrm{U}$ were assayed by liquid scintillation counting. Spec. pure $\mathrm{Eu}_{2} \mathrm{O}_{3}(>99.99 \%)$ was used to prepare stock solutions for the luminescence spectroscopic studies. Suprapur (Merck) nitric acid was used after proper dilutions and the concentrations were measured by standard acid-base titration methods. ${ }^{10}$

\subsection{Radiotracer solutions}

Typically, the metal ion concentrations used for the solvent extraction experiments were $\sim 10^{-7} \mathrm{M}$ for $\mathrm{Am}, \sim 10^{-6} \mathrm{M}$ for $\mathrm{Pu}$, and $10^{-5} \mathrm{M}$ for both $\mathrm{U}$ and $\mathrm{Eu}$. The valency state of Pu was adjusted to the +4 state by adding a few drops of $5.0 \times 10^{-2} \mathrm{M}$ $\mathrm{NaNO}_{2}$ solution into a beaker containing the Pu tracer mixture in $1 \mathrm{M} \mathrm{HNO}_{3} . \mathrm{Pu}^{4+}$ was separated by selective extraction into an organic phase containing $0.5 \mathrm{M}$ TTA (2-thenoyltrifluoroacetone) in xylene followed by stripping into $8 \mathrm{M} \mathrm{HNO}_{3}{ }^{11} \mathrm{On}$ the other hand, $\mathrm{Pu}$ was converted to its +6 oxidation state by adding a few $\mathrm{mg}$ of $\mathrm{AgO}$ into the Pu solution in $1 \mathrm{M} \mathrm{HNO}_{3}$ and subsequently destroying the unreacted $\mathrm{AgO}$ by mild heating under an IR lamp. ${ }^{12}$ The valency state of Pu in the +4 or the +6 state was checked by carrying out TTA concentration variation experiments, which resulted in slope-values of +4 or +2 (due to the $\mathrm{PuO}_{2}{ }^{2+}$ species), respectively. ${ }^{13}$

\subsection{Solvent extraction studies}

Solvent extraction studies were carried out by vortexing equal volumes (usually $1 \mathrm{~mL}$ ) of the ligand solution in a suitable diluent and dilute nitric acid solution containing the required radiotracers in leak-tight stoppered Pyrex glass tubes in a thermostated water bath at $25 \pm 0.1{ }^{\circ} \mathrm{C}$ for about $1 \mathrm{~h}$. It was checked by independent experiments that $1 \mathrm{~h}$ of equilibration was sufficient to attain equilibrium. Subsequent to the phase mixing, the tubes were centrifuged and the phases were separated and assayed radiometrically (usually $100 \mu \mathrm{L}$ aliquots were taken for radiometric assay). The radiometric assay of ${ }^{233} \mathrm{U}$ and $\mathrm{Pu}$ was done with an alpha-liquid scintillation
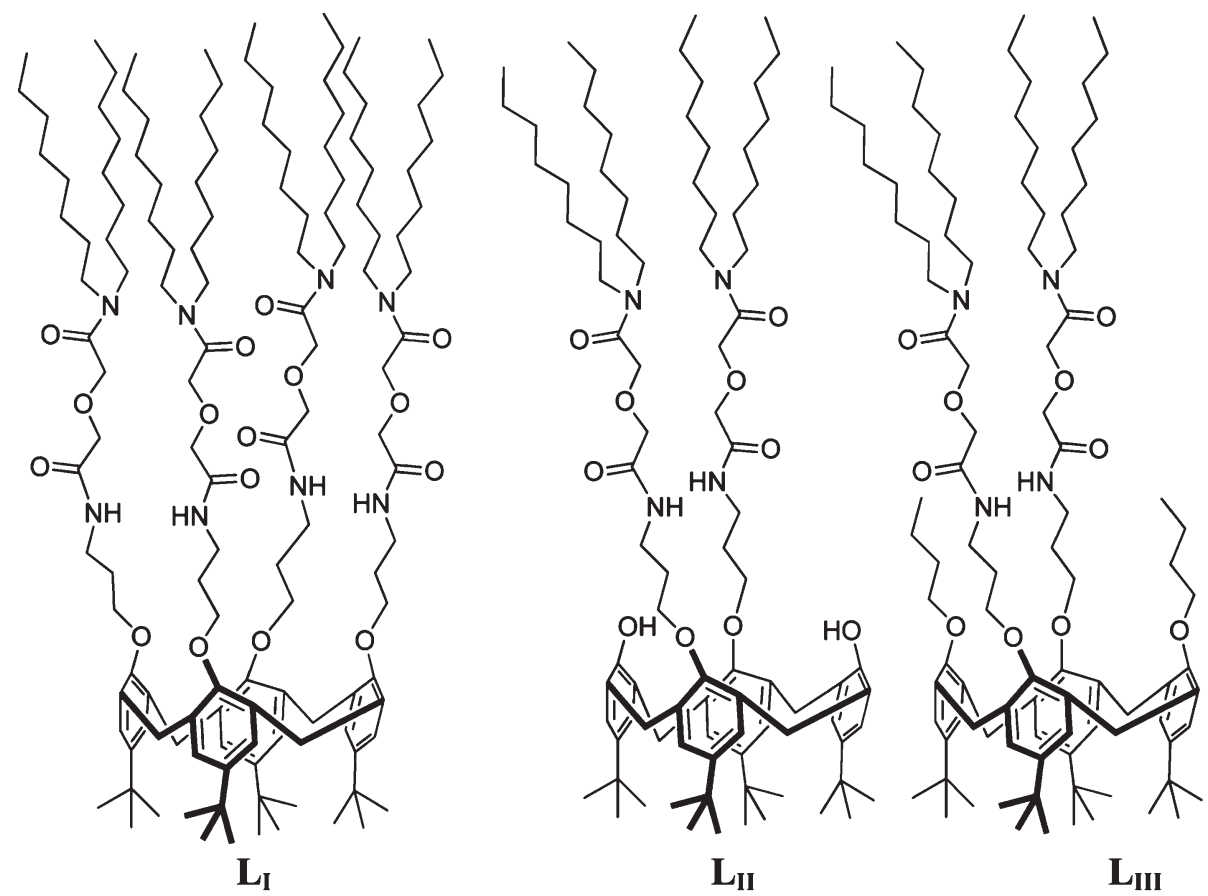

Fig. 1 Structural formulae of the DGA-Calix ligands $\mathbf{L}_{1}, \mathbf{L}_{11}$, and $\mathbf{L}_{\text {III }}$. 
counting system (Hidex, Finland) using an Ultima Gold scintillator cocktail (Sisco Research Laboratory, Mumbai), while that of ${ }^{85,89} \mathrm{Sr},{ }^{137} \mathrm{Cs}$ and ${ }^{239} \mathrm{~Np}$ was carried out by gamma ray counting using a $\mathrm{NaI}(\mathrm{Tl})$ scintillation counter (Para Electronics, India) interphased to a multi-channel analyzer (ECIL, India).

The distribution ratio of a particular metal, $D_{\mathrm{M}}$, was defined as the ratio of the concentration of the metal ion per unit volume in the organic phase to that in the aqueous phase. The separation factor (SF) was defined as the ratio of the distribution ratio values. All solvent extraction experiments were carried out in duplicate with a precision of $\pm 5 \%$.

\subsection{Fluorescence studies}

The laser-induced luminescence measurements were carried out using a fluorescence spectrometer (Edinburgh Analytical Instruments, UK) controlled by a CD 920 controller and pumped by OPO lasers as the excitation sources. The pulse repetition rate was kept constant at $10 \mathrm{~Hz}$ for lifetime measurements and the excitation wavelength was fixed at $395 \mathrm{~nm}$, while emission spectra were recorded in the range of $575-750 \mathrm{~nm}$.

\subsection{Theoretical calculations}

Density functional calculations were performed to optimize the geometries of the bare ligands and the metal-ligand complexes. All of the lighter atoms were treated at the all electron level and the standard $\operatorname{def}-\mathrm{SV}(\mathrm{P})$ basis sets were used. However, for the $\mathrm{Eu}$ atom, 28 electron core pseudo-potentials (ECP) along with the corresponding (14s13p10d8f1g)/ [10s9p5d4f1g] basis set were selected. ${ }^{14}$ Becke's exchange functional ${ }^{15}$ in conjunction with Perdew's correlation functional $^{16}$ (BP86) with the generalized gradient approximation (GGA) was used in all density functional calculations. The geometrical parameter i.e. bond lengths and stability parameter i.e. complexation energy values were calculated for all the complexes, as were the charge distribution values, calculated by natural population analysis. All calculations were carried out using the TURBOMOLE program package. ${ }^{17}$

\section{Results and discussion}

\subsection{Solvent extraction studies}

The extraction of $\mathrm{Am}^{3+}$ and $\mathrm{Eu}^{3+}$ was reported by us in a recent communication. ${ }^{5}$ It was observed that the extraction of the metal ions was significantly higher when the DGA-functionalized calix[4]arene contained four DGA pendent arms $\left(\mathbf{L}_{\mathbf{I}}\right.$, Fig. 1) as compared to those with two DGA arms $\left(\mathbf{L}_{\mathbf{I I}}\right.$ and $\mathbf{L}_{\mathbf{I I I}}$, Fig. 1). The $D_{\mathbf{M}}$ values for Am and Eu with $\mathbf{L}_{\mathbf{I}}$ were about 25 and 29 times higher as compared to those of $\mathbf{L}_{\mathbf{I I}}$, while they were 663 and 554 times higher than those of $\mathbf{L}_{\text {III }}$. The very low metal ion extraction ability of $\mathbf{L}_{\text {III }}$ was attributed to the steric crowding by the two butyl groups. The basicities of the extractants were determined by a standard procedure ${ }^{18}$ and were found to be comparable to that of TODGA, which was reported to be $4.1 .^{18}$
TODGA is known to show preference for the extraction of $\mathrm{Eu}^{3+}$ over $\mathrm{Am}^{3+}{ }^{19}$ A similar preference was observed for ligands $\mathbf{L}_{\mathbf{I}}-\mathbf{L}_{\text {III }}$, though the $\mathrm{SF}\left(D_{\mathrm{Eu}} / D_{\mathrm{Am}}\right)$ values are somewhat lower than that of TODGA. While $\mathbf{L}_{\mathbf{I}}$ and $\mathbf{L}_{\mathbf{I I}}$ yielded $\mathrm{SF}$ values close to $5, \mathbf{L}_{\text {III }}$ showed a $\mathrm{SF}$ value of around 7 . This could be due to higher uncertainties associated with the lower $D_{\mathrm{M}}$ values obtained with $\mathbf{L}_{\text {III }}$. SF values are reported to be dependent on the nature of the diluent. ${ }^{19,20}$ Therefore, it was of interest to investigate the behaviour of the extraction of $\mathrm{Am}^{3+}$ and $\mathrm{Eu}^{3+}$ with different diluents. The results, as shown in Table 1 , indicate that though a rough trend of increasing $D_{\mathrm{Am}}$ and to some extent $D_{\mathrm{Eu}}$ can be seen with the dielectric constant (ESI†), lower than expected values were obtained in the case of chloroform which can be attributed to the H-bonding tendency of the diluent. ${ }^{24}$ On the other hand, the higher extraction seen in case of $n$-dodecane is not clearly understood. Though one may attribute it to a similar reverse micelle formation as in case of TODGA, the low concentration of the ligand almost rules out that. Nitrobenzene with a high dielectric constant $(35.6)^{21}$ extracts both metal ions favourably, though a reversal in the extraction trend was seen, i.e., $\mathrm{Am}^{3+}$ was extracted to a higher extent than $\mathrm{Eu}^{3+}$. Favourable extraction of the metal ions was also observed with other high dielectric constant diluents such NPOE (2-nitrophenyloctyl ether) and hexone (methyl isobutyl ketone), though the SF values were favourable towards $\mathrm{Eu}^{3+}$.

The extraction mechanism with neutral diglycolamide ligands is given as:

$$
\mathbf{M}^{n+}+n \mathrm{NO}_{3}{ }^{-}+m \mathrm{~L}_{\mathrm{org}} \rightarrow \mathrm{M}\left(\mathrm{NO}_{3}\right)_{n} \cdot m \mathrm{~L}_{\mathrm{org}}
$$

where the species with the subscript 'org' refer to those present in the organic phase while those without any subscript refer to those present in the aqueous phase. The two-phase extraction constant $\left(K_{\mathrm{ex}}\right)$ is expressed as

$$
K_{\mathrm{ex}}=\frac{\left[\mathrm{M}\left(\mathrm{NO}_{3}\right)_{n} \cdot m \mathrm{~L}\right]_{\mathrm{org}}}{\left[\mathrm{M}^{n+}\right]\left[\mathrm{NO}_{3}^{-}\right]^{n}[\mathrm{~L}]_{\mathrm{org}}^{m}}
$$

where the species with low concentration are expressed as concentration terms. As the distribution ratio is defined as the ratio of the metal ion concentrations in the organic phase to that in the aqueous phase, eqn (2) can be rearranged to:

$$
\log D_{\mathrm{M}}=\log K_{\mathrm{ex}}+n \log \left[\mathrm{NO}_{3}{ }^{-}\right]+m \log [\mathrm{L}]_{\mathrm{org}}
$$

The nature of the extracted species was determined from the $\log D_{\mathrm{M}}$ vs. $\log [\mathrm{L}]_{\text {org }}$ plots obtained from the ligand concentration variation experiments. Table 1 lists the slopes of the plots along with the $R^{2}$ values for nitrobenzene, NPOE, hexone, and $n$-dodecane for $\mathrm{Am}^{3+}$ extraction. For other diluents, such studies were not carried out due to the lower $D_{\mathrm{Am}}$ values. The results suggested 1 : 1 extracted species for hexone and NPOE, while 1:2 species were observed for $n$-dodecane and nitrobenzene. The $1: 2$ species is rather difficult to rationalize as it would involve 16 amidic and 8 ethereal ' $O$ ' atoms to form bonds with the metal ions. Similar studies carried out for $\mathrm{Eu}^{3+}$ indicated $1: 1$ species extracted with $\mathbf{L}_{\mathbf{I}}$, while $1: 2$ species were observed for both $\mathbf{L}_{\text {II }}$ and $\mathbf{L}_{\text {III }}$ (Fig. 2). Participation of $2 \mathbf{L}_{\mathbf{I}}$ 
Table 1 Role of organic diluent on $\mathrm{Am}\left(\mathrm{III} / \mathrm{Eu}(\mathrm{III})\right.$ extraction using $\mathbf{L}_{1}$; aq. phase: $3 \mathrm{M} \mathrm{HNO}_{3}$

\begin{tabular}{|c|c|c|c|c|c|}
\hline Nitrobenzene & 35.6 & 221 & 252 & 0.88 & $2.1 \pm 0.1(0.984)^{d}$ \\
\hline Hexone & $13.1^{22}$ & 38.7 & 8.52 & 4.54 & $1.0 \pm 0.1(0.981)^{d}$ \\
\hline$n$-dodecane & 2.012 & 53.4 & 9.83 & 5.43 & $1.9 \pm 0.1(0.993)^{d}$ \\
\hline Carbon tetrachloride & 2.24 & 0.42 & 0.07 & 6.00 & - \\
\hline Benzene & 2.28 & 0.83 & 0.20 & 4.15 & - \\
\hline
\end{tabular}

species in the case of $\mathrm{Am}^{3+}$, in sharp contrast to only one ligand molecule in the case of $\mathrm{Eu}^{3+}$, is rather unusual and could not be explained. Apparently, this should exclude some of the donor atoms from coordinating to the metal ion. In view of the paste-like mass obtained with the $\mathrm{Eu}^{3+}-\mathbf{L}_{\mathbf{I}}$ complex, it was not possible to carry out X-ray structural analysis.

Acid concentration variation studies were carried out for $\mathrm{Am}^{3+}$ and $\mathrm{Eu}^{3+}$ extraction in the acidity range of $0.01 \mathrm{M}$ to $6 \mathrm{M}$ $\mathrm{HNO}_{3}$ using $1.13 \times 10^{-3} \mathrm{M} \mathrm{L}_{\mathbf{I}}$ in $n$-dodecane. While $\mathrm{Am}^{3+}$ extraction was found to be higher than that of $\mathrm{Eu}^{3+}$ at lower acidities (0.01-2 M), a reversal in the extraction trend was seen beyond $2 \mathrm{M} \mathrm{HNO}_{3}$ (Fig. 3). The SF values go through a maximum at $3 \mathrm{M} \mathrm{HNO}_{3}$, which coincidentally is the acidity of the HLW (high level waste). Extraction of other actinide ions such as $\mathrm{Np}^{4+}, \mathrm{Pu}^{4+}, \mathrm{UO}_{2}{ }^{2+}, \mathrm{NpO}_{2}{ }^{2+}$, and $\mathrm{PuO}_{2}{ }^{2+}$ was also investigated at $3 \mathrm{M} \mathrm{HNO}_{3}$ using $1.13 \times 10^{-3} \mathrm{M} \mathrm{L}_{\mathbf{I}}$ and the results are presented in Fig. 4 . The SF values with respect to $\mathrm{Am}^{3+}$ are also included in the figure. The trend of actinide ion extraction was $\mathrm{M}^{4+}>\mathrm{M}^{3+}>\mathrm{MO}_{2}{ }^{2+}$, which is different from that observed with TODGA. ${ }^{19}$ A similar extraction trend was observed at about three times higher ligand concentration. ${ }^{5}$ This confirms the fact that the unusual preferential extraction of $\mathrm{Am}^{3+}$ with respect to $\mathrm{Pu}^{4+}$ and $\mathrm{UO}_{2}{ }^{2+}$ observed in case of

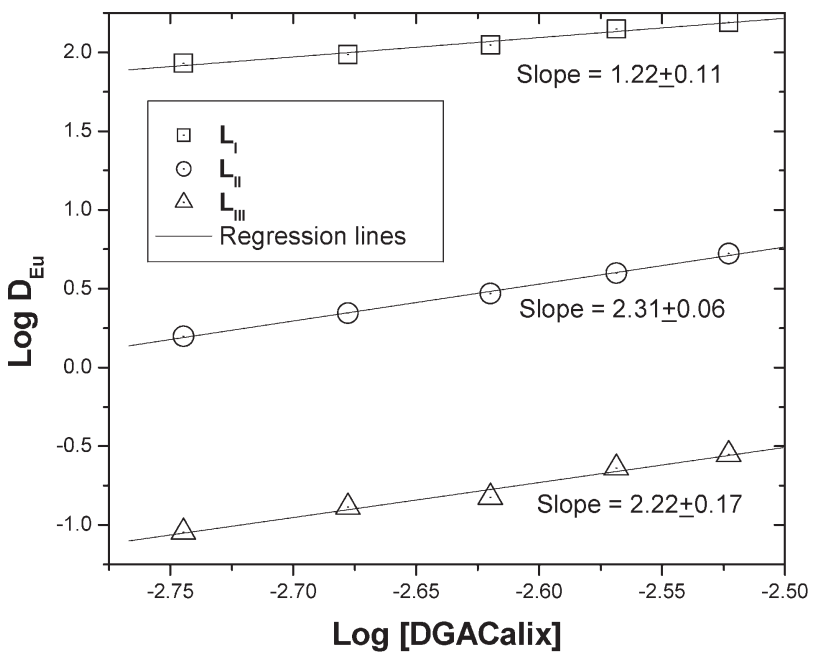

Fig. 2 Dependence of $\mathrm{Eu}^{3+}$ extraction on ligand concentration. Aqueous phase: $3 \mathrm{M} \mathrm{HNO}_{3}$.
TODGA, which was attributed to reverse micelle formation involving four TODGA molecules, apparently does not take place with the DGA-Calix ligand. However, though $\mathrm{UO}_{2}{ }^{2+}$ is extracted by ligands such as CMPO and malonamides ${ }^{25}$ to a much higher extent than $\mathrm{Am}^{3+}$, it was negligibly extracted by the DGA-Calix extractant, $\mathbf{L}_{\mathbf{I}}$. A similar extraction behaviour was also seen with the other hexavalent actinide ions $\mathrm{NpO}_{2}{ }^{2+}$ and $\mathrm{PuO}_{2}{ }^{2+}$. The $\mathrm{SF}$ values are not very impressive from the point of view of the separation of tetravalent ions, though separation from hexavalent ions appears quite feasible (Fig. 4).

\subsection{Fluorescence spectroscopic studies}

The $\mathrm{Eu}^{3+}$ ion is known to exhibit well-characterized emission spectra in the visible region due to transitions identified as ${ }^{5} \mathrm{D}_{0}$ $\rightarrow{ }^{7} \mathrm{~F}_{2}(617 \mathrm{~nm}),{ }^{5} \mathrm{D}_{0} \rightarrow{ }^{7} \mathrm{~F}_{1}(592 \mathrm{~nm})$ and ${ }^{5} \mathrm{D}_{0} \rightarrow{ }^{7} \mathrm{~F}_{4}(690 \mathrm{~nm}) .{ }^{26}$ The intensity of the $\mathrm{Eu}^{3+}$ luminescence changes in the metalligand complexes relative to that in the aquo ion are due to changes in symmetry upon complexation. ${ }^{27}$ Fig. 5 shows the luminescence spectra of $\mathrm{Eu}^{3+}$ resulting from the titration of metal ions with the ligand. The characteristic peaks observed at 591,617 , and $692 \mathrm{~nm}$ correspond to the de-excitation of the ${ }^{5} \mathrm{D}_{0}$ level to the ${ }^{7} \mathrm{~F}_{1},{ }^{7} \mathrm{~F}_{2}$, and ${ }^{7} \mathrm{~F}_{4}$ levels of $\mathrm{Eu}^{3+}$, respectively. The

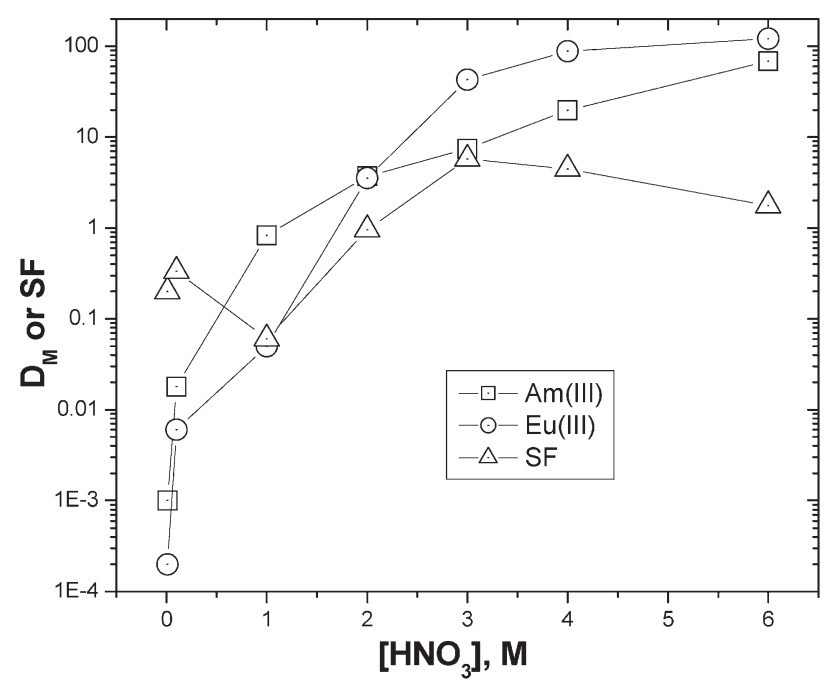

Fig. 3 Dependence of $\mathrm{Am}^{3+}$ and $\mathrm{Eu}^{3+}$ extraction on aqueous phase nitric acid concentration. Organic phase: $1.13 \times 10^{-3} \mathrm{M} \mathrm{L}_{\mathbf{l}}$ in $n$-dodecane. 


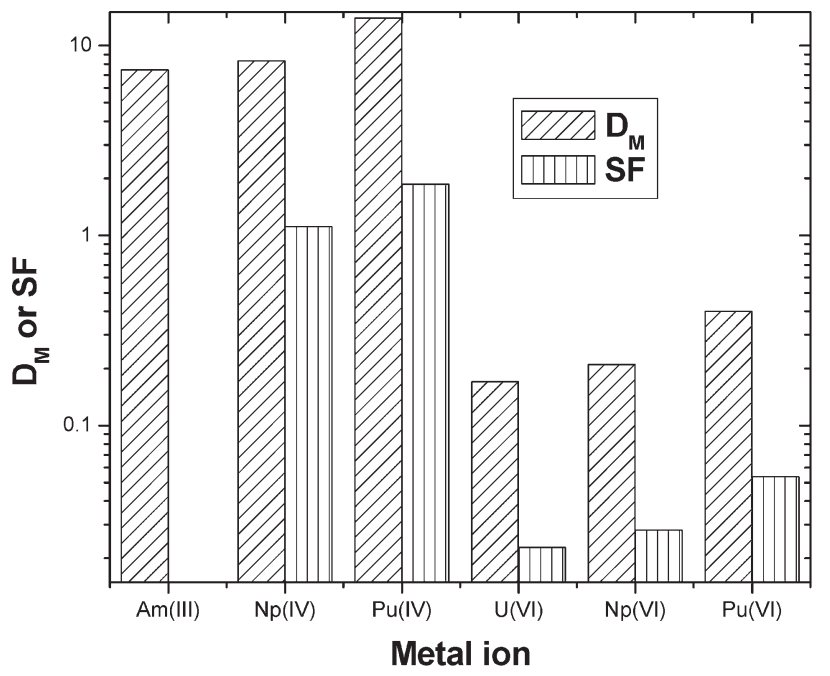

Fig. 4 Relative extraction of several actinide ions in the tri-, tetra- and hexavalent states using $1.13 \times 10^{-3} \mathrm{M} \mathrm{L}_{\mathbf{1}}$ in $n$-dodecane as the organic phase and $3 \mathrm{M} \mathrm{HNO}_{3}$ as the aqueous phase.

transition corresponding to ${ }^{5} \mathrm{D}_{0} \rightarrow{ }^{7} \mathrm{~F}_{2}$ is a hypersensitive transition, and is extremely sensitive to the ligand field. As is clear from Fig. 5, the peak intensity corresponding to the $\mathrm{Eu}^{3+}$ aqua ion is minimal, but increases upon complexation with the ligand, while in addition splitting of the $617 \mathrm{~nm}$ peak occurs. These features are a clear indication of the complexation of the $\mathrm{Eu}^{3+}$ ion with the ligand, $\mathbf{L}_{\mathbf{I}}$. The luminescence intensity at a fixed wavelength is proportional to the

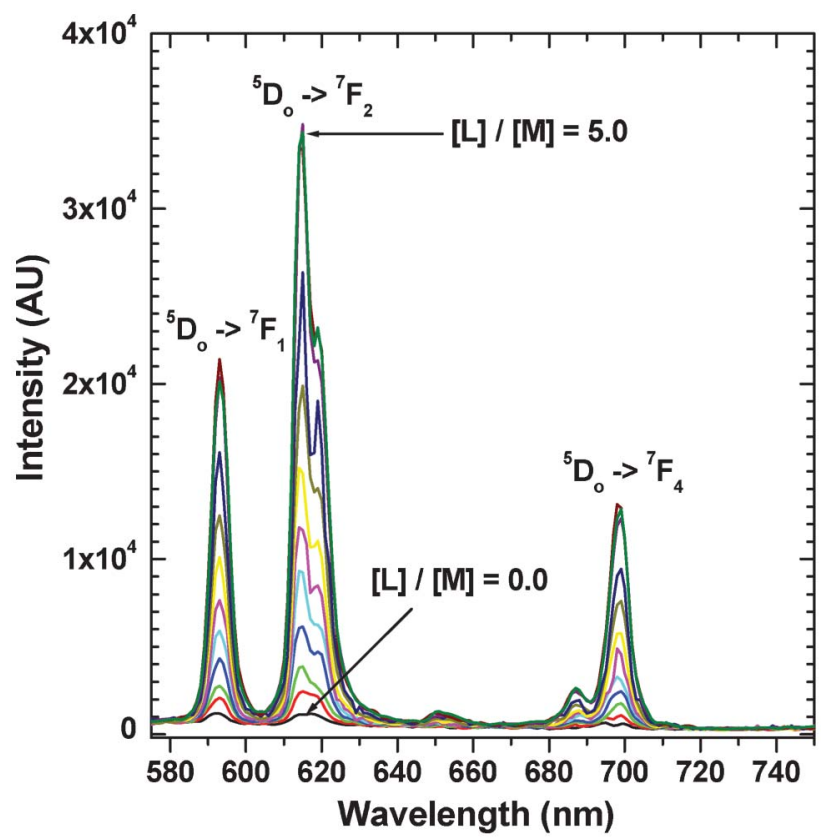

Fig. 5 Evolution of luminescence spectra of $\mathrm{Eu}^{3+}$ solution containing $10^{-5} \mathrm{M}$ $\mathrm{Eu}\left(\mathrm{NO}_{3}\right)_{3}$ and increasing amounts of ligand (ligand-to-metal ratio $=0.0,0.05$, $0.1,0.2,0.3,0.4,0.6,0.8,1.0,1.5,2.0$, and 5.0). Diluent: ethanol-water (5: 1) in aqueous nitrate medium at $\mathrm{pH}$; excitation wavelength: $395 \mathrm{~nm}$. concentration of $\left[\mathrm{Eu} \cdot \mathbf{L}_{\mathbf{I}}\right]^{3+}$, and that was the basis for the calculation of different fractions of $\mathrm{Eu}^{3+}$ ions in the solution at equilibrium.

The lifetime of the $\mathrm{Eu}^{3+}$ ion was measured from the luminescence decay curve to identify the number of $\mathrm{Eu}^{3+}$ species present in the solution. ${ }^{28}$ A typical lifetime spectrum is shown in Fig. 6. In the absence of the ligand, the lifetime of the metal ion in $5: 1$ ethanol-water medium was about $150 \pm$ $15 \mu \mathrm{s}$, which suggests that all the coordination sites of the $\mathrm{Eu}^{3+}$ ion are hydrated in the form of $\left[\mathrm{Eu}\left(\mathrm{H}_{2} \mathrm{O}\right)_{9}\right]^{3+}$, and the higher lifetime is due to the effects of the medium. ${ }^{29}$ In the presence of the ligand $\mathbf{L}_{\mathbf{I}}$, at a $\mathrm{L}: \mathrm{M}$ ratio $=0.1$, two species are clearly seen as the spectrum shows two slopes. This feature is an indication that part of the Eu exists as $\left[\mathrm{Eu}\left(\mathrm{H}_{2} \mathrm{O}\right)_{8-9}\right]^{3+}$ and the other part as a $\left[\mathrm{Eu} \cdot \mathbf{L}_{\mathbf{I}}\right]^{3+}$ complex. This behaviour was also observed with increasing $\mathrm{L}: \mathrm{M}$ ratios up to 1.5. However, at a $\mathrm{L}: \mathrm{M}$ ratio $=2$, only one slope was present corresponding to the $[\mathrm{Eu} \cdot \mathrm{L}]^{3+}$ complex. This feature suggested that all water molecules from the primary coordination sphere of the cation were replaced by the ligand and consequently there was no $\left[\mathrm{Eu}\left(\mathrm{H}_{2} \mathrm{O}\right)_{8-9}\right]^{3+}$ species in the solution. Therefore, the spectrum at $\mathrm{L}: \mathrm{M}$ ratio $\geqslant 2$ in Fig. 5 can be considered as characteristic for the $\left[\mathrm{Eu} \cdot \mathbf{L}_{\mathbf{I}}\right]^{3+}$ complex. The total emission intensities arising from ${ }^{5} \mathrm{D}_{0} \rightarrow{ }^{7} \mathrm{~F}_{0-4}$ observed for Eu ions without any addition of ligand $(\mathrm{L}=0)$ and for $\mathrm{L}$ : $\mathrm{M}$ ratio of 5 were therefore considered to arise from $10^{-6} \mathrm{M}\left[\mathrm{Eu}\left(\mathrm{H}_{2} \mathrm{O}\right)_{8-9}\right]^{3+}$ and $\left[\mathrm{Eu} \cdot \mathbf{L}_{\mathbf{I}}\right]^{3+}$ complex species, respectively. It should be noted that only $\left[\mathrm{Eu}\left(\mathrm{H}_{2} \mathrm{O}\right)_{8-9}\right]^{3+}$ and one $\mathrm{Eu} \cdot \mathbf{L}_{\mathbf{I}}$ species seems to exist in the solution at all intermediate metal-to-ligand ratios as the decay curves were observed to be biexponential and spectra in the intermediate $\mathrm{L}: \mathrm{M}$ ratios change mainly as regards intensity. The lifetime data are given separately in Table 2 . Solvent extraction indicated a slope value of $1.20 \pm 0.03$ also suggesting extraction of $1: 1$ $\mathbf{M}: \mathbf{L}_{\mathbf{I}}$ species (Table 1).

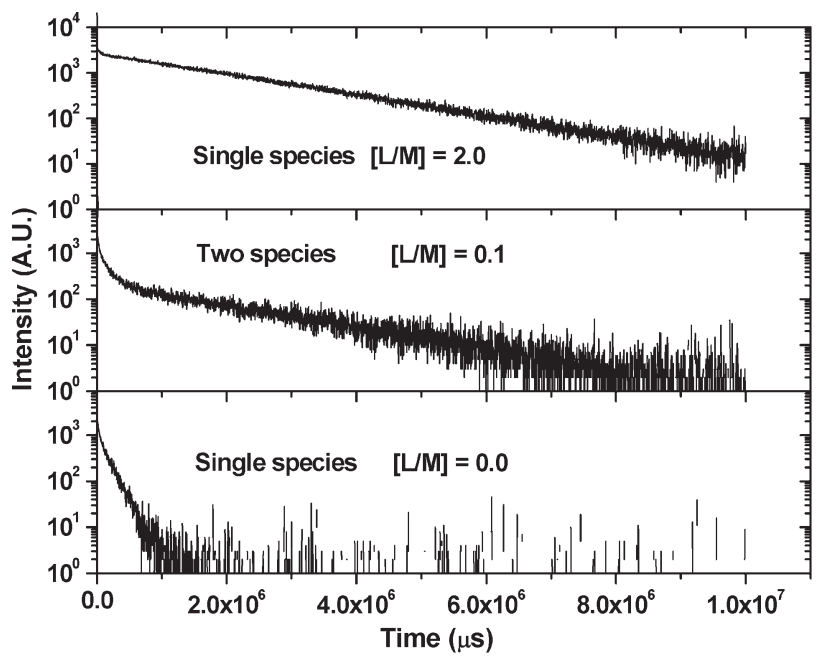

Fig. 6 Evolution of the luminescence decay curve for $\mathrm{Eu}^{3+}$ solution containing $10^{-5} \mathrm{M} \mathrm{Eu}\left(\mathrm{NO}_{3}\right)_{3}$ and increasing amounts of ligand (ligand-to-metal ratio $=0.0$, 0.1, and 2.0). Diluent: ethanol-water (5:1) in aqueous nitrate medium at $\mathrm{pH} 3$; excitation wavelength: $395 \mathrm{~nm}$. 
Table 2 Lifetime (in microseconds) data for the complexation of Eu(III) with $\mathbf{L}_{\mathbf{1}}$. Values in the parentheses refer to the lifetimes of the uncomplexed Eu(III) species

\begin{tabular}{ll}
\hline $\mathrm{L}:$ M ratio & \multicolumn{1}{c}{ Lifetime } \\
\hline 0.0 & $(144)$ \\
0.1 & $(133)^{a} 1741$ \\
1 & $1833^{b}$ \\
2 & $1902^{c}$ \\
5 & $1899^{c}$
\end{tabular}

${ }^{a}$ The fraction of the uncomplexed species was $25 \%{ }^{b}$ About $1.2 \%$ of the total Eu was found to be uncomplexed. ${ }^{c}$ The entire amount of Eu was found to be present as complexed species with $\mathbf{L}_{\mathbf{I}}$.

For the determination of the stability constant of the M-L complex, it is necessary to obtain $\left[\mathrm{Eu}_{\text {complexed }} / \mathrm{Eu}_{\text {free }}\right]$ for different $\mathrm{L}: \mathrm{M}$ ratios. The complexation equilibria for $\mathrm{Eu}^{3+}$ and $\mathbf{L}_{\mathbf{I}}$ (presented as L) can be represented as follows:

$$
\mathrm{Eu}^{3+}+n \mathrm{~L} \stackrel{\beta}{\longleftrightarrow} \mathrm{Eu} \cdot \mathrm{L}_{n}^{3+}
$$

where $\beta$ is the conditional stability constant, and can be given as:

$$
\beta=\frac{\left[\mathrm{Eu} \cdot \mathrm{L}_{n}\right]^{3+}}{[\mathrm{Eu}]_{\text {Free }}^{3+} \cdot[\mathrm{L}]_{\text {Free }}^{n}}
$$

The above equation can be solved as:

$$
\log \left[\frac{[\mathrm{Eu}]_{\text {complex }}}{[\mathrm{Eu}]_{\text {free }}}\right]=\log \beta+n \log [\mathrm{L}]_{\text {free }}
$$

where $[\mathrm{Eu}]_{\text {complex }}$ is the europium complexed with the ligand, $\left[\mathrm{Eu} \cdot \mathrm{L}_{\mathrm{n}}\right]^{3+}$. For a given europium species, the luminescence intensity at a fixed wavelength is proportional to its concentration in solution. When 5 molar equivalents of the DGACalix ligand $\mathbf{L}_{\mathbf{I}}$ are added, no un-complexed europium remains in the solution, so the only europium species present in solution is the $\left[\mathrm{Eu} \cdot \mathrm{L}_{\mathrm{n}}\right]^{3+}$ complex. The luminescence spectrum obtained for a given ligand-to-metal ratio can be adjusted with a linear combination of the spectra of the un-complexed and complexed $\mathrm{Eu}^{3+}$; these two spectra being perfectly known. The coefficients of the linear combination allow the determination of the relative proportions of the two species, $[\mathrm{Eu}]_{\text {free }}$ and $[\mathrm{Eu}]_{\text {complex }}$, present in the solution at thermodynamic equilibrium. Knowing the amount of ligand that was initially added, it is possible to calculate the remaining free ligand concentration and then the conditional stability constant of the $\left[\mathrm{Eu} \cdot \mathrm{L}_{\mathrm{n}}\right]^{3+}$ complex can be calculated. Fig. 7 shows the linear log-log plot as shown in eqn (6). The linear regression fit of the data yielded a slope value of $0.98 \pm 0.15(\sim 1)$, confirming the formation of a $1: 1$ metal-to-ligand complex. The $\log \beta$ value calculated from the slope was $6.23 \pm 0.37$. The $\log \beta$ value obtained by the present method is comparable to the overall complex formation constant reported for TODGA in ethanol. ${ }^{29}$ In view of the presence of four TODGA molecules in

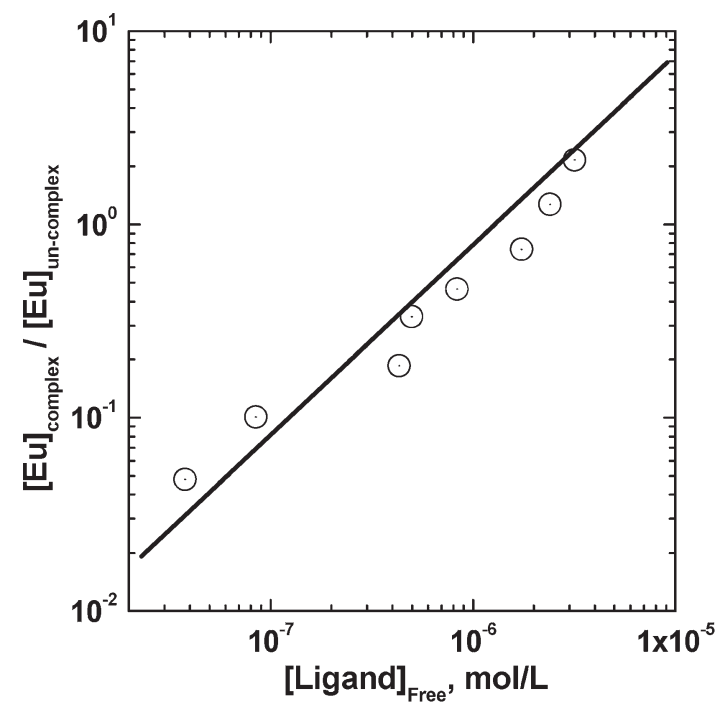

Fig. 7 Plot of the ratio of complexed Eu to free Eu as a function of free ligand concentration. Diluent: ethanol-water $(5: 1)$ in aqueous nitrate medium at $\mathrm{pH} 3$.

the formation of complexes with $\mathrm{Eu}^{3+}$, the present results are in good agreement with those reported as the four DGA moieties in ligand $\mathbf{L}_{\mathbf{I}}$ are equivalent to the four independent TODGA molecules. No calculation was made for the complexation of $\mathrm{Eu}^{3+}$ with $\mathbf{L}_{\mathbf{I I}}$ and $\mathbf{L}_{\mathbf{I I I}}$ due to the very small changes in the spectra compared to the aquo complex.

\subsection{Theoretical calculations}

Density functional optimized structures of the metal-ligand complexes are depicted in Fig. 8. Among the three complexes, Eu- $\mathbf{L}_{\mathbf{I}}$ is octa-coordinated and the other two complexes with $\mathbf{L}_{\mathbf{I I}}$ and $\mathbf{L}_{\text {III }}$ are hexa-coordinated. Calculated metal-ligand bond lengths are given in Table 3. From the bond length values it is clear that the $\mathrm{M}-\mathrm{L}$ bond lengths are maximum for $\mathbf{E u}-\mathbf{L}_{\mathbf{I}}$, which is due to the higher coordination, but at the same time it is also more stable. Metal-ligand bond distances in $\mathbf{E u}-\mathbf{L}_{\mathbf{I I I}}$ are higher compared to those in $\mathbf{E u}-\mathbf{L}_{\mathbf{I I}}$, which may be due to the steric hindrance provided by the butyl groups present in $\mathbf{L}_{\text {III }}$. Hence, bond lengths are much shorter for the Eu- $\mathbf{L}_{\mathbf{I I}}$ complex. It has to be noted that there is not much difference between the complexation energies of Eu- $\mathbf{L}_{\text {III }}$ and $\mathbf{E u}-\mathbf{L}_{\mathbf{I I}}(0.23$ eV) (Table 3), however, there are considerable differences in bond lengths. Earlier, similar trends have been reported ${ }^{30}$ for actinide and lanthanide complexes with terpy and Me-BTP ligands. So, it is predicted that $\mathbf{L}_{\mathbf{I I}}$ is likely to be more selective for Eu(III) than $\mathbf{L}_{\text {III }}$. However, in case of $\mathbf{L}_{\text {III }}$ a higher selectivity was reported for $\mathrm{Eu}^{3+}$ extraction as compared to $\mathrm{Am}^{3+}$ extraction (Table 1). Calculated partial atomic charge values (Table 4) indicate that the metal-ligand bonding is more ionic in the $\mathbf{E u}-\mathbf{L}_{\mathbf{I I}}$ complex than in the Eu- $\mathbf{L}_{\text {III }}$ complex.

\section{Conclusions}

The present study is a comparative evaluation of the DGAfunctionalized calix[4] arene ligands $\mathbf{L}_{\mathbf{I}}-\mathbf{L}_{\mathbf{I I I}}$ for $\mathrm{Am}^{3+}$ and $\mathrm{Eu}^{3+}$ 


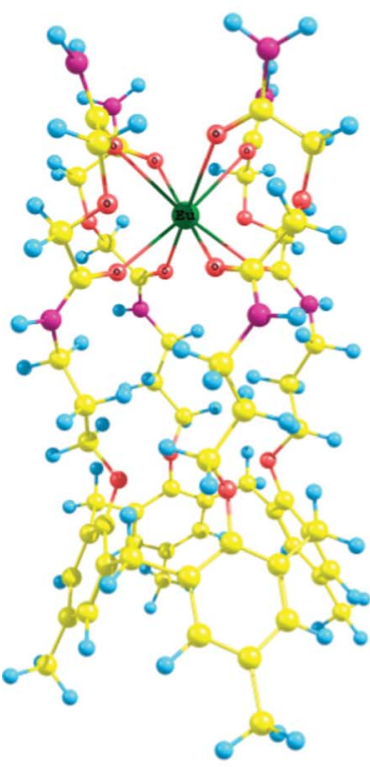

Eu-L $\mathbf{I}$

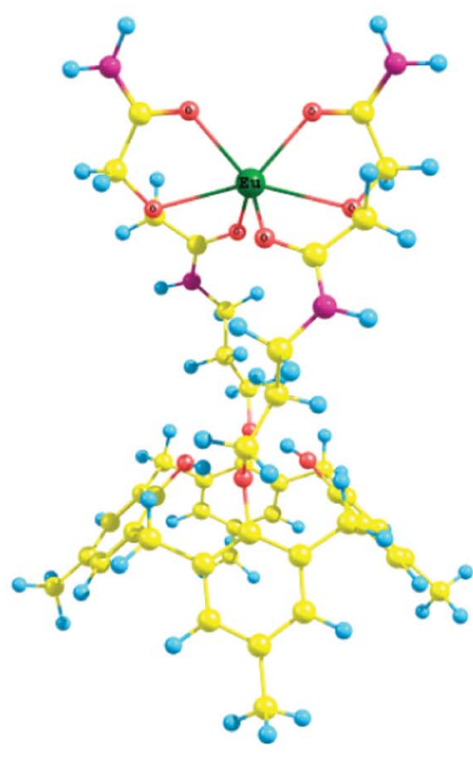

Eu-L II

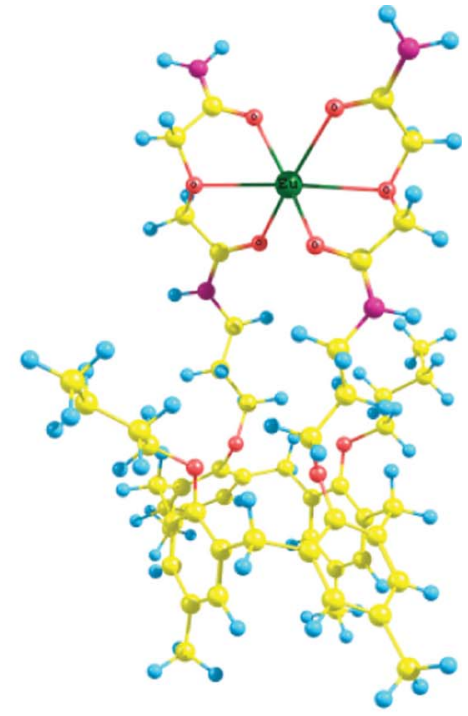

Eu-L III

Fig. 8 Optimized structures of various metal-ligand complexes.

Table 3 Calculated metal-ligand bond length and complexation energy values for various $[\mathrm{ML}]^{3+}$ complexes

\begin{tabular}{|c|c|c|c|c|}
\hline Complex & $d_{\mathrm{Eu}-\mathrm{O}}($ ether $)$ & $d_{\mathrm{Eu}-\mathrm{O}}($ carbonyl) & $d_{\mathrm{Eu}-\mathrm{O}}($ carbonyl $)$ & Complexation energy $(\mathrm{eV})$ \\
\hline $\mathrm{Eu}-\mathbf{L}_{\mathbf{I}}$ & 3.488 (nonbonding) & 2.537 & 2.702 & -30.63 \\
\hline $\mathrm{Eu}-\mathbf{L}_{\mathbf{I I}}$ & 2.693 & 2.298 & 2.361 & -25.98 \\
\hline $\mathrm{Eu}-\mathbf{L}_{\mathbf{I I I}}$ & 2.717 & 2.354 & 2.455 & -26.21 \\
\hline
\end{tabular}

extraction. The role of the nature of the organic diluent is illustrated in the case of the highly polar nitrobenzene giving rise to the formation of an unusual $1: 2$ complex in the case of $\mathbf{L}_{\mathbf{I}}$. In the other diluents used, $1: 1$ complexes were formed in case of $\mathrm{Am}^{3+}$ and $\mathrm{Eu}^{3+}$ with $\mathbf{L}_{\mathbf{I}}$, containing four DGA moieties, while $1: 2$ species were extracted with ligands $\mathbf{L}_{\mathbf{I I}}$ and $\mathbf{L}_{\mathbf{I I I}}$, having two DGA pendent groups. Luminescence studies involving $\mathrm{Eu}^{3+}$ with $\mathbf{L}_{\mathbf{I}}$ indicated strong complex formation as concluded from the removal of all the inner-sphere water molecules. The complex formation constant of the Eu- $\mathbf{L}_{\mathbf{I}}$ complex was also computed and was found to be comparable to that obtained with four TODGA molecules.

Table 4 Calculated atomic charge values for various $[\mathrm{ML}]^{3+}$ complexes on metal and donor centers

\begin{tabular}{|c|c|c|c|c|}
\hline Complex & $q_{\mathrm{Eu}}($ ether) & $q_{\mathrm{o}}$ (carbonyl) & $q_{\mathrm{o}}($ carbonyl) & $q_{\mathrm{O}}$ (ether) \\
\hline $\mathrm{Eu}-\mathbf{L}_{\mathbf{I}}$ & 1.615 & -0.739 & -0.691 & -0.604 \\
\hline $\mathrm{Eu}-\mathbf{L}_{\mathbf{I I}}$ & 1.769 & -0.774 & -0.718 & -0.614 \\
\hline Eu-L $\mathbf{L}_{\text {III }}$ & 1.691 & -0.746 & -0.696 & -0.607 \\
\hline
\end{tabular}

\section{Acknowledgements}

The authors (D.R.R., P.K.M., S.A.A. and S.V.G.) are thankful to Dr A. Goswami, Head, Radiochemistry Division for his constant encouragement.

\section{References}

1 (a) G. R. Choppin and A. Morgenstern, J. Radioanal. Nucl. Chem., 2000, 243, 45-51; (b) P. A. Baisden and G. R. Choppin, Nuclear waste management and the nuclear fuel cycle, in Radiochemistry and Nuclear Chemistry, ed. S. Nagyl, Eolss Publishers, Encyclopedia of Life Support Systems (EOLSS), Oxford, U.K., 2007.

2 S. A. Ansari, P. N. Pathak, P. K. Mohapatra and V. K. Manchanda, Chem. Rev., 2012, 112, 1751-1772.

3 S. A. Ansari, P. N. Pathak, P. K. Mohapatra and V. K. Manchanda, Sep. Purif. Rev., 2011, 40, 43-76.

4 (a) M. P. Jensen, T. Yaita and R. Chiarizia, Langmuir, 2007, 23, 4765-4774; (b) T. Yaita, A. W. Herlinger, P. Thiyagarajan and M. P. Jensen, Solvent Extr. Ion Exch., 2004, 22, 553-571; (c) P. N. Pathak, S. A. Ansari, S. Kumar, B. S. Tomar and V. K. Manchanda, J. Colloid Interface Sci., 2010, 342, 114-118. 
5 P. K. Mohapatra, M. Iqbal, D. R. Raut, W. Verboom, J. Huskens and S. V. Godbole, Dalton Trans., 2012, 41, 360-363.

6 C. Schmidt, M. Saadioui, V. Böhmer, V. Host, M. R. Spirlet, J. F. Desreux, F. Brisach, F. Arnaud-Neu and J.-F. Dozol, Org. Biomol. Chem., 2003, 1, 4089-4096.

7 (a) M. Iqbal, P. K. Mohapatra, S. A. Ansari, J. Huskens and W. Verboom, Tetrahedron, 2012, 68, 7840-7847; (b) A. Sengupta, P. K. Mohapatra, M. Iqbal, J. Huskens and W. Verboom, Dalton Trans., 2012, 41, 6970-6979.

8 (a) M. Albin, G. K. Farber and W. D. Horrocks, Inorg. Chem., 1984, 23, 1648-1651; (b) A. Gunther, G. Geipel and G. Bernhard, Polyhedron, 2007, 26, 59-65; (c) H. G. Brittain, Inorg. Chem., 1980, 19, 640-643; (d) A. Heller, A. Barkleit, G. Bernhard and J. U. Ackermann, Inorg. Chim. Acta, 2009, 362, 1215-1222.

9 P. K. Mohapatra, PhD Thesis, University of Bombay, 1993.

10 G. H. Jeffery, J. Bassett, J. Mendham and R. C. Denney, Vogel's Textbook of Quantitative Chemical Analysis, Addison Wesley Longman Limited, Singapore, 1996.

11 (a) The Chemistry of Actinide Elements, ed. J. J. Katz, G. T. Seaborg and L. R. Morss, 2nd edn., Chapman and Hall, New York, 1986; (b) P. K. Mohapatra, P. B. Ruikar and V. K. Manchanda, Radiochim. Acta, 2002, 90, 323-327.

12 (a) J. M. Cleveland, The Chemistry of Plutonium, Gordon and Breach Science Publishers, New York, 1970; (b) P. N. Pathak, D. R. Prabhu, G. H. Rizvi, P. B. Ruikar, L. B. Kumbhare, P. K. Mohapatra and V. K. Manchanda, Radiochim. Acta, 2003, 91, 379-384.

13 V. K. Manchanda, P. N. Pathak and P. K. Mohapatra, New developments in thorium, uranium and plutonium extraction, in Ion Exchange and Solvent Extraction, ed. B. A. Moyer, CRC Press, Boca Raton, vol. 1021, pp. 69-71.

14 (a) M. Dolg, H. Stoll and H. Preuss, Energy-adjusted ab initio pseudopotentials for the rare earth elements, $J$. Chem. Phys., 1989, 90, 1730; (b) X. Cao and M. Dolg, Valence basis sets for relativistic energy-consistent smallcore lanthanide pseudopotentials, J. Chem. Phys., 2001, 115, 7348; (c) W. Kuchle, M. Dolg, H. Stoll and H. Preuss, Energy-adjusted pseudopotentials for the actinides. Parameter sets and test calculations for thorium and thorium monoxide, J. Chem. Phys., 1994, 100, 7535; (d) Valence basis sets for relativistic energy-consistent small- core actinide pseudopotentials, X. Cao, M. Dolg and H. Stoll, J. Chem. Phys., 2003, 118, 487; (e) Segmented contraction scheme for small-core actinide pseudopotential basis sets, X. Cao and M. Dolg, THEOCHEM, 2004, 673, 203.

15 A. D. Becke, Phys. Rev. A, 1988, 38, 3098-3100.

16 J. P. Perdew, Phys. Rev. B, 1986, 33, 8822-8824.

17 R. Ahlrichs, M. Bär, M. Häser, H. Horn and C. Kölmel, Chem. Phys. Lett., 1989, 162, 165-169.

18 R. B. Gujar, S. A. Ansari, M. S. Murali, P. K. Mohapatra and V. K. Manchanda, J. Radioanal. Nucl. Chem., 2010, 284, 377-385.

19 Y. Sasaki, Y. Sugo, S. Suzuki and S. Tachimori, Solvent Extr. Ion Exch., 2001, 19, 91-109.

20 S. Panja, P. K. Mohapatra, S. C. Tripathi, P. M. Gandhi and P. Janardan, J. Membr. Sci., 2012, 403-404, 71-77.

21 W. M. Haynes, Handbook of Chemistry and Physics, CRC Press, Florida, 1992.

22 http://www.monumentchemical.com/documents/ MIBK_Data_and_Safety_Sheet.pdf.

23 J. Chen, H. Boerrigter and A. C. Veltkamp, Radiochim. Acta, 2001, 89, 523-528.

24 (a) Y. Marcus, Solvent Extr. Ion Exch., 1989, 7, 567-575; (b) Y. Marcus, Chem. Soc. Rev., 1993, 409-416.

25 (a) W. Schulz and E. P. Horwitz, Sep. Sci. Technol., 1988, 23, 1191-1210; (b) E. P. Horwitz and D. G. Kalina, Solvent Extr. Ion Exch., 1984, 2, 179-200; (c) W. W. Schulz and E. P. Horwitz, ACS Symp. Ser., 1999, 716, 20-50; (d) J. N. Mathur, M. S. Murali and K. L. Nash, Solvent Extr. Ion Exch., 2008, 19, 357-390.

26 (a) W. D. Horrocks and D. R. Sudnick, J. Am. Chem. Soc., 1979, 101, 334-340; (b) W. D. Horrocks and D. R. Sudnick, Acc. Chem. Res., 1981, 14, 384-392.

27 (a) G. R. Choppin and D. R. Peterman, Coord. Chem. Rev., 1998, 174, 283-299; (b) W. D. Horrocks and D. R. Sudnick, J. Am. Chem. Soc., 1979, 101, 334-340; (c) T. Kimura and Y. Kato, J. Alloys Compd., 1998, 278, 92-97.

28 P. Zhang and T. Kimura, Solvent Extr. Ion Exch., 2006, 24, 149-163.

29 P. N. Pathak, S. A. Ansari, S. V. Godbole, A. R. Dhobale and V. K. Manchanda, Spectrochim. Acta, Part A, 2009, 73, 348-352.

30 D. Guillaumont, J. Phys. Chem. A, 2004, 108, 6893-6900. 